\title{
Resuscitation of patients with cardiac arrest by ambulance staff with extended training in West Yorkshire
}

\author{
D Wright, J Bannister, M Ryder, A F Mackintosh
}

Abstract
Objective-To investigate the results of resuscita-
tion of patients with cardiac arrest by ambulance
staff with extended training in West Yorkshire.
Design-Study of all such attempts at resuscitation
over 32 months, based on the standard report form
for each call made by the ambulance staff and the
electrocardiogram that showed the initial rhythm in electrocardio

Setting-Area covered by West Yorkshire ambulance service.

Subjects-1196 Patients with cardiac arrests attended by 29 ambulance staff with extended training.

Main outcome measure-Result of resuscitation.

Results-The initial rhythm was asystole or electromechanical dissociation in $\mathbf{7 4 0}$ patients and ventricular fibrillation in 456 patients; overall 65 patients survived to be discharged from hospital. Sixty four of the 456 patients in whom ventricular fibrillation was the initial rhythm recorded, and 46 in whom ventricular fibrillation persisted after the ambulance staff arrived, survived. Only one of the 740 patients who initially had asystole or electromechanical dissociation survived. Factors associated with a greater chance of ventricular fibrillation occurring were: age less than 71 , the arrest being witnessed by a bystander, resuscitation by a bystander, the arrest occurring in a public place, and a response time by the ambulance staff of less than six minutes. For patients found in ventricular fibrillation a shorter response time was associated with improved survival but resuscitation by a bystander was not. Additional skills learnt during extended training were used for 51 of the 65 patients who survived.

Conclusions-Ambulance staff with extended training can save the lives of patients with cardiac arrest due to fibrillation, though asystole and electromechanical dissociation have a poor prognosis and should perhaps receive little attention during extended training.

St James's University Hospital, Leeds LS9 7TF

D Wright, MRCP, cardiology registrar

J Bannister, BSC, senior physicist

M Ryder, research technician A F Mackintosh, FRCP, consultant cardiologist

Correspondence to: $\mathrm{Dr}$ Mackintosh.

BrMed F 1990;301:600-2

\section{Introduction}

In the past four years the NHS Training Authority's guidelines for extended training have been implemented in the United Kingdom to provide selected ambulance staff with advanced resuscitation skills including skill in defibrillation, endotracheal intubation, giving drugs, and replacing fluids. ${ }^{1}$ In addition to treating a wide range of emergencies trained staff will attempt resuscitation for all types of cardiopulmonary arrests.

We have previously reported the results of defibrillation by staff with extended training in a single year. ${ }^{2}$

TABLE I - Initial rhythm in electrocardiogram and outcome in 1196 patients after cardiac arrest

\begin{tabular}{lcccc}
\hline Initial rhythm & No & $\begin{array}{c}\text { Resuscitation } \\
\text { initially successful }\end{array}$ & $\begin{array}{c}\text { Patients stabilised and } \\
\text { admitted to hospital }\end{array}$ & $\begin{array}{c}\text { Patients discharged } \\
\text { from hospital }\end{array}$ \\
\hline Ventricular fibrillation & 456 & 179 & 127 & 64 \\
Asystole & 585 & 57 & 25 & 1 \\
Electromechanical dissociation & 155 & 19 & 3 & 65 \\
\hline Total & 1196 & 255 & 155 & 6 \\
\hline
\end{tabular}

In the present study we report the results of all attempts to resuscitate people who had had a cardiac arrest by these staff from January 1987 to August 1989.

\section{Patients and methods}

The West Yorkshire ambulance service attends a predominantly urban population of $2 \cdot 2$ million. Five of the nine health districts have at least some ambulance staff with extended training (paramedical staff). During the first 21 months of the study, as described previously, ${ }^{2}$ these staff were sent out in a rapid response vehicle backed up by a conventional ambulance. From October 1988 this system was stopped and the emergency service was separated from the routine ambulances, with paramedical staff being sent out in some of the emergency vehicles. Nine of these paramedical staff were available at the beginning of the study, increasing to 29 by the end.

A standard report form was completed for each call, and the electrocardiogram that showed the initial rhythm in each patient was retained for later analysis. Victims of trauma, suffocation, and drowning were not included. In several cases ventricular fibrillation occurred during resuscitation but was not the initial rhythm. The response time was defined as the time between the call being received by the member of the paramedical staff and his or her arrival at the scene. A witnessed arrest was defined as loss of consciousness in the presence of a bystander. Resuscitation by a bystander indicated that some attempt at basic life support, including resuscitation by a doctor or other ambulance staff, was in progress when the paramedical staff arrived.

Resuscitation was defined as initially successful if cardiac ouptut was restored. Some of these patients were stabilised and admitted to hospital. Survivors were defined as patients who were discharged from hospital. Twenty eight of the 1196 record forms were incomplete in some respect. Statistical analysis was by $\chi^{2}$ test with Yates's correction for small numbers.

\section{Results}

The staff with extended training attended cardiac arrests in 1196 patients aged 18-97. Table I gives the overall results. Of the 740 patients with asystole or electromechanical dissociation as the initial rhythm, only one survived, an 18 year old with asthma who developed asystole in the presence of the ambulance staff. Ventricular fibrillation occurred during resuscitation in 141 patients who had asystole or electromechanical dissociation initially.

The factors associated with a higher incidence of ventricular fibrillation compared with other types of cardiac arrest were age less than 71 , the occurrence of the arrest in a public place, the presence of a witness, resuscitation by a bystander, and a response time shorter than six minutes (table II). All the factors favouring ventricular fibrillation were present in 57 patients, of whom $42(74 \%)$ had arrests due to ventricular fibrillation. In contrast, 42 patients did not have any of these factors, and six (14\%) of them had arrests due to ventricular fibrillation. The mean 


\begin{tabular}{|c|c|c|c|c|c|c|}
\hline & \multicolumn{2}{|c|}{ No (\%) of arrests } & \multirow[b]{2}{*}{$\%$ Difference } & \multirow[b]{2}{*}{$\begin{array}{c}95 \% \text { Confidence } \\
\text { interval }\end{array}$} & \multirow[b]{2}{*}{$\chi^{2}$ Value } & \multirow[b]{2}{*}{ p Value } \\
\hline & $\begin{array}{l}\text { Due to ventricular } \\
\text { fibrillation }\end{array}$ & $\begin{array}{l}\text { Not due to ventricular } \\
\text { fibrillation }\end{array}$ & & & & \\
\hline $\begin{array}{l}\text { Age }<71 \\
\text { Male patient } \\
\text { Witnessed by paramedical staff }\end{array}$ & $\begin{array}{r}342(75) \\
265(58) \\
46(10)\end{array}$ & $\begin{array}{l}\text { All arrests } \\
475(64) \\
465(63) \\
50(7)\end{array}$ & $\begin{array}{r}11 \\
-5 \\
3\end{array}$ & $\begin{array}{l}6 \text { to } 16 \\
-10 \text { to } 1 \\
0 \text { to } 6\end{array}$ & $\begin{array}{r}14 \cdot 77 \\
2 \cdot 45 \\
3 \cdot 80\end{array}$ & $\begin{array}{l}0 \cdot 001 \\
0 \cdot 117 \\
0.051\end{array}$ \\
\hline Total & 456 & 740 & & & & \\
\hline \multicolumn{7}{|c|}{ Arrests not witnessed by paramedical staff } \\
\hline $\begin{array}{l}\text { Witnessed by bystander } \\
\text { Resuscitation by bystander }\end{array}$ & $358(87)$ & $\begin{array}{l}491(71) \\
155(22)\end{array}$ & 16 & 11 to 21 & $\begin{array}{r}37 \cdot 21 \\
105 \cdot 28\end{array}$ & $\begin{array}{l}<0.0001 \\
<0.0001\end{array}$ \\
\hline $\begin{array}{l}\text { Kesuscitation by bystander } \\
\text { Response time of paramedical }\end{array}$ & $217(53)$ & $155(22)$ & 30 & 25000 & $105 \cdot 28$ & $<0001$ \\
\hline staff $<6 \mathrm{~min}$ & $204(50)$ & $251(36)$ & 13 & 7 to 19 & $18 \cdot 43$ & $<0.0001$ \\
\hline Arrest occurred in public place & $168(41)$ & $132(19)$ & 22 & 16 to 27 & $60 \cdot 78$ & $<0.0001$ \\
\hline Total & 410 & 690 & & & & \\
\hline
\end{tabular}

TABLE III - Factors that may affect survival of patients with ventricular fibrillation

\begin{tabular}{|c|c|c|c|c|c|c|}
\hline & \multicolumn{2}{|c|}{$\begin{array}{l}\text { No (\%) of patients with ventricular } \\
\text { fibrillation initially }\end{array}$} & \multirow[b]{2}{*}{ \% Difference } & \multirow{2}{*}{$\begin{array}{l}95 \% \text { Confidence } \\
\text { interval }\end{array}$} & \multirow[b]{2}{*}{$\chi^{2}$ Value } & \multirow[b]{2}{*}{$\mathrm{p}$ Value } \\
\hline & Survived & Did not survive & & & & \\
\hline \multicolumn{7}{|c|}{ All arrests } \\
\hline Age $<71$ & $49(77)$ & $294(75)$ & 2 & -10 to 13 & 0.01 & 0.929 \\
\hline Male patient & $34(53)$ & $231(59)$ & -6 & -19 to 6 & 0.54 & 0.462 \\
\hline Witnessed by paramedical staff & $26(41)$ & $20(5)$ & 36 & 23 to 43 & $72 \cdot 68$ & $<0.0001$ \\
\hline Total & 64 & 392 & & & & \\
\hline \multicolumn{7}{|c|}{ Arrests not witnessed by paramedical staff } \\
\hline Witnessed by bystander & $35(92)$ & $323(87)$ & 5 & -4 to 16 & 0.46 & $0 \cdot 500$ \\
\hline Resuscitation by bystander & $24(63)$ & $193(52)$ & 11 & -5 to 27 & $1 \cdot 34$ & $0 \cdot 248$ \\
\hline \multirow{3}{*}{$\begin{array}{l}\text { Response time of paramedical } \\
\text { staff }<6 \mathrm{~min} \\
\text { Arrest occurred in public } \\
\text { place }\end{array}$} & & & & & & \\
\hline & $28(74)$ & $176(47)$ & 26 & 11 to 43 & 8.57 & 0.003 \\
\hline & $21(55)$ & $147(40)$ & 16 & -1 to 32 & $2 \cdot 91$ & 0.088 \\
\hline Total & 38 & 372 & & & & \\
\hline
\end{tabular}

response time was 6.4 minutes, with $75 \%(877 / 1196)$ of the patients being reached within $7 \cdot 7$ minutes.

Sixty four of the 65 survivors had ventricular fibrillation initially. Fibrillation starting in the presence of paramedical staff was followed by the survival of $57 \%(26 / 46)$ of patients. A response time of less than six minutes was also associated with a higher chance of survival (table III). The oldest survivor was 89 years old. Additional skills learnt during extended training were needed for many of the patients with ventricular fibrillation. The 65 survivors required a mean of two electric shocks (maximum six); 49 received drugs (adrenaline, atropine, and lignocaine), and 38 were intubated.

\section{Discussion}

This is the first large scale study of the use of the NHS Training Authority's extended training for cardiac arrests out of hospital. Our results emphasise the importance of defibrillation out of hospital. Altogether $14 \%(64 / 456)$ of the patients with cardiac arrest due to ventricular fibrillation survived to leave hospital, a success rate comparable with those in other reports of resuscitation out of hospital. ${ }^{3-5}$ In common with other workers ${ }^{67}$ we found that resuscitation of patients with asystole and electromechanical dissociation seldom led to long term survival, although initial success and admission to hospital were not uncommon. The 690 cases of asystole and electromechanical dissociation that occurred before an ambulance arrived did not yield any survivors.

With these poor results for cardiac arrest not due to fibrillation it is worth assessing the factors associated with a greater chance of an arrest being due to ventricular fibrillation. Many of the factors that were positively associated-for example, the arrest being witnessed by a bystander, cardiopulmonary resuscitation by a bystander, and a short response time-may be related to a shorter total duration of the arrhythmia and some alleviation of its effects; with time many episodes of fibrillation may progress to asystole. As described before, age less than 71 is also associated with a greater incidence of ventricular fibrillation, ${ }^{8}$ but this may be because fewer older patients received resuscitation by a bystander. Although these factors may have some importance, no single factor allows an ambulance controller to say that a particular cardiac arrest is probably or probably not due to ventricular fibrillation.

A response time of less than six minutes improves the chances of survival of patients in whom ventricular fibrillation occurs before the ambulance arrives. This has been well shown previously. ${ }^{910}$ Resuscitation by a bystander may help, " but this study was not sufficiently large to show this. With a few exceptions results are poor in unwitnessed arrests. The chances of survival after defibrillation are not appreciably worse in patients over 70 . The survival rate of $57 \%$ among patients in whom fibrillation develops after the ambulance has arrived or during transit is comparable with the results of defibrillation in a coronary care unit. ${ }^{12}$

The number of staff with extended training available during the study was small, and no area had cover for 24 hours a day. Despite this an appreciable number of patients who developed ventricular fibrillation outside hospital survived. Many ambulance authorities including West Yorkshire now give semiautomatic, advisory defibrillators to staff who have not had extended training. It is not yet established whether comparable results can be obtained. In this study the skills learnt during extended training were used for 52 of the 65 survivors, though how much these manoeuvres contributed to their recovery is impossible to assess. Defibrillation outside hospital is certainly worth while, though the optimum mixture of staff with extended training and other staff using advisory defibrillators remains to be determined. Asystole and electromechanical dissociation that occur outside hospital continue to 
have a poor prognosis and should perhaps receive little attention during extended training.

We are grateful for the help of West Yorkshire metropolitan ambulance service and the many health service staff who participate in extended training.

1 Ambulance Staff Training Committee. Extended training in ambulance aid Bristol: NHS Training Authority, 1987

2 Wright D, James C, Marsden AK, Mackintosh AF. Defibrillation by ambulance staff who have had extended training. Br Med f 1989;299:96-7. 3 Eisenberg MS, Hallstrom A, Bergner L. Long term survival after out of hospital cardiac arrest. $N$ Engl f Med 1982;306:1340-3.

4 Shults KR, Braun DD, Schug VL, Bean JA. Prehospital defibrillation performed by emergency medical technicians in rural communities. $N E n g l$ fMed 1984;310:219-23.

5 Jackobssen J, Nyquist O, Rehnquist N. Effects of early defibrillation of out-of hospital cardiac arrest patients by ambulance personnel. Eur Heart $\mathcal{J}$ $1987 ; 8: 1189-94$
6 Myerburg RJ, Estes D, Zaman L, et al. Outcome of resuscitation from bradyrhythmic or asystolic prehospital cardiac arrest. $\mathcal{I} \mathrm{Am}$ Coll Cardiol 1984;4:1118-22.

7 Iseri LT, Humphrey SB, Siner EJ. Prehospital brady-asystolic cardiac arrest. Ann Intern Med 1978;88:741-3.

8 Tresch DD, Thakur R, Hoffman RG, Brodis HL. Comparison of outcome of out-of-hospital cardiac arrest in persons younger and older than 70 years of out-of-hospital cardiac arrest in perso
age. Am f Cardiol 1988;61:1120-2.

9 Eisenberg MS, Berger L, Hallstrom AP. Cardiac resuscitation in the community. Importance of rapid provision and implications for programme planning. J AMA 1979;241:1905-8.

10 Weaver WD, Cobb LA, Hallstrom AP, Fahrenbruch C, Copass MK, Ray R. Factors influencing survival after out-of-hospital cardiac arrest. $\mathcal{F} \mathrm{Am} \mathrm{Coll}$ Cardiol 1986;8:752-7.

11 Rutter G, Wolfe RA, Goldstein S, et al. The effects of bystander cardiopulmonary resuscitation on survival of out-of-hospital cardiac arrest victims. Am Heart F 1985;110:932-7.

12 Mackintosh AF, Crabb ME, Brennan $\mathrm{H}$, Williams JH, Chamberlain DA. Hospital resuscitation from ventricular fibrillation in Brighton. $\mathrm{Br}$ Med $\mathcal{f}$ $1979 \cdot \mathrm{i} \cdot 511-3$.

(Accepted lo July 1990)
To avoid neonatal subglottic stenosis a Cole tube should not be used for ventilation

\title{
Lesson of the Week
}

\section{Dangers of neonatal intubation with the Cole tube}

\author{
M D Mitchell, C M Bailey
}

Tracheal intubation is an accepted part of modern neonatal intensive care. Although basically a safe procedure, it is not without complications. ${ }^{\text {S Subglottic }}$ stenosis is the most serious of these with a reported incidence in one series of $2.6 \%$ in long term survivors of tracheal intubation. ${ }^{2}$ Reports have repeatedly drawn attention to the high incidence of subglottic stenosis after tracheal intubation with a Cole pattern shouldered tracheal tube.$^{34}$ Despite these reports this tube is still widely used, particularly by non-anaesthetists.

\section{Case report}

A 14 day old male infant was referred to this hospital because of repeated failures at extubation at the referring hospital. The infant, weighing $1400 \mathrm{~g}$ at birth, had been delivered by emergency caesarean section at 37 weeks' gestation because of intrauterine growth retardation and a suspected diaphragmatic hernia. He needed resuscitation, and tracheal intubation had been performed one minute after delivery; he had then been transferred to the intensive care unit for further resuscitation and ventilation. A chest radiograph had not shown a diaphragmatic hernia. He had recovered and had been extubated when he was 26 hours old. Three hours subsequently, however, he had collapsed and had been reintubated and resuscitated. During the next 11 days three further trials of extubation had been attempted, dexamethasone being given on the last attempt to reduce glottic oedema. On each occasion he had collapsed, but between trials of extubation he had breathed well and maintained good arterial oxygen tensions. A Cole pattern tracheal tube had been used for each intubation.

Microlaryngoscopy and bronchoscopy were performed on the day after admission to this hospital. After induction of anaesthesia the child was reintubated. Slight posterior displacement of the larynx allowed the glottis to be seen clearly at laryngoscopy, and the shoulder of the oral Cole tube (size $3.0 \mathrm{~mm}$ ) was seen to be well through the glottis. This tube was removed to permit inspection of the glottis and was replaced with a $2.5 \mathrm{~mm}$ parallel sided nasotracheal tube. After completing the preparations for surgery the new tube was removed to permit microlaryngoscopy and bronchoscopy with a $2.5 \mathrm{~mm}$ Storz bronchoscope with assisted ventilation. The upper gum was severely ulcerated and grooved at the site of the shouldered tracheal tube, the vocal cords were barely identifiable, and there was severe glottic and subglottic damage with circumferential ulceration in the shape of the tube. The child subsequently needed an elective tracheostomy and may eventually require laryngotracheal reconstruction for established subglottic stenosis.

\section{Discussion}

This case illustrates the severe laryngeal damage that may follow the use of a Cole pattern shouldered tracheal tube. Cole introduced the shouldered tube to reduce resistance to airflow by restricting the narrowing to a short intratracheal portion. ${ }^{6}$ The shoulder, however, causes an abrupt transition from laminar to turbulent air flow and therefore actually increases resistance to air flow, thus removing the proposed advantage of its design. ${ }^{7}$ Its shape and relative stiffness make it easy to use and hence it enjoys considerable popularity and is commonly used by paediatricians for resuscitating newborn infants. If, however, a Cole tube is left in position for longer term airway management its wide shoulder may advance through the vocal cords to impact in the non-expansile cricoid region. Necroscopic findings and animal research have confirmed that ulceration and necrosis of the mucosa may then occur within hours, leading to the onset of subglottic stenosis. ${ }^{2}$

These changes may also occur with parallel sided tracheal tubes, but damage may be minimised and possibly avoided altogether by paying careful attention to detail when selecting and using tracheal tubes. The correct sized tube must be chosen. ${ }^{8}$ Strong and Passay showed that half the tracheal tubes used in a series of patients in their unit were too large. ${ }^{1}$ There should be a leak around the tube, as first suggested by Stocks, when pressure of $25 \mathrm{~cm} \mathrm{H}_{2} \mathrm{O}$ is applied to the breathing circuit. ${ }^{9}$ The tube must be the correct length, which should be calculated before intubation and confirmed afterwards by chest radiography. ${ }^{8}$ The intubation must be performed as smoothly as possible to avoid trauma to the mucosa. Adequately secure fixation must be achieved, the only way of ensuring this being to pass the tube nasotracheally and to attach it to the forehead using a Tunstall type connector. Orotracheal intubation 